\title{
The electrocardiogram in apparently healthy men and the risk of sudden death
}

\author{
SIMON W RABKIN, F A L MATHEWSON, R B TATE \\ From the Department of Medicine, Faculty of Medicine, University of Manitoba, Winnipeg, Manitoba, Canada
}

SUMMARY The purpose of this study was to determine whether electrocardiographic abnormalities detected on a routine examination in men without clinical evidence of heart disease predicted sudden death in the absence of pre-existing clinical manifestations of heart disease. The Manitoba study consists of a cohort of 3983 men with a mean age at entry of 30.8 years who have been followed with regular examinations including electrocardiograms since 1948. During the 30 year observation period, 70 cases of sudden death have occurred in men without previous clinical manifestations of heart disease. The prevalence of electrocardiographic abnormalities before sudden death was $71.4 \%$ (50/70). The frequency of abnormalities was $31.4 \%$ (22) major ST segment and T wave abnormalities, $15.7 \%$ (11) ventricular extrasystoles, $12.9 \%$ (nine) left ventricular hypertrophy (voltage criteria), $7 \cdot 1 \%$ (five) complete left bundle-branch block, and $5 \cdot 7 \%$ (four) pronounced left axis deviation. When these electrocardiographic findings in men without clinical manifestations of heart disease were related prospectively to incidence of sudden death each one except pronounced left axis deviation was a significant predictor of sudden death. Two of the variables were examined in more detail. Increased severity of primary $\mathrm{T}$ wave abnormalities and the association of ST segment and $\mathrm{T}$ wave abnormalities with increased QRS voltage further increased sudden death risk. The combination of ventricular extrasystoles with either ST-T abnormalities or left ventricular hypertrophy much increased the risk of sudden death. Thus these data indicate that electrocardiographic abnormalities detected on routine examination in men without clinical evidence of heart disease are significantly related to the occurrence of sudden death.

Sudden death has become recognised as a major challenge in contemporary cardiology with the realisation that it is the most frequent mode of death in ischaemic heart disease..$^{1-3}$ Investigations of this problem have mainly centred on sudden death in patients with known cardiac disease and there are comparatively few data available in men without previous clinical evidence of ischaemic heart disease. Because in this circumstance it is their first and usually their last clinical manifestation of heart disease, it is especially important to identify high risk groups for sudden death. The electrocardiogram which is in widespread use primarily as a diagnostic tool is less often used in prognosis especially as it relates to apparently healthy subjects. Yet the electrocardiogram is used in the screening of healthy individuals in many settings and represents a simple non-invasive method of cardiac assessment that may be of value in risk stratification.

Accepted for publication 11 February 1982
The purpose of this investigation was to examine the hypothesis that the "routine" electrocardiogram in apparently healthy men is predictive of sudden death.

\section{Subjects and methods}

The details of this study have been reported previously. ${ }^{45}$ In summary, the cohort consists of 3983 men, who during the second world war were either pilots or pilots in training in the Royal Canadian Air Force, or pilots licensed by the Department of Transport and who at the time had a routine electrocardiogram in addition to the regular medical examination. After release from the service, some continued to fly but the majority found different occupations and are in all strata of society.

For each subject, the examination closest to 30 June 1948 (date population was defined) was selected as the entry examination. The age distribution at entry was as follows: 318 men were aged 15 to 
24 years, 1479 aged 25 to 29,1258 aged 30 to 34,539 aged 35 to 39, 205 aged 40 to 44,153 aged 45 to 54, and 31 aged 55 to 64 years. Earlier medical information and examinations provided evidence that they were without clinical manifestations of ischaemic heart disease at entry. Since then, they have been followed by annual letters with medical examinations and electrocardiograms at intervals of at first five and later three years. The observation period was defined from 1 July 1948 until 30 June 1978, an average follow-up of 30 years. Annual contact has been lost with only two persons.

\section{DEFINITIONS AND CASE DETECTIONS}

Cases were selected if they had (1) electrocardiographic abnormality detected during a routine examination, and (2) no clinical evidence of ischaemic or valvular heart disease on either that examination or the previous ones since entry. Thus, men with myocardial infarction, angina pectoris, or coronary insufficiency before the detection of the electrocardiographic abnormalities were excluded. The diagnostic criteria used for these manifestations of ischaemic heart disease were outlined previously. ${ }^{5}$ For myocardial infarction, this included detection of new abnormal ( $\geqslant 0.03 \mathrm{~s}) \mathrm{Q}$ wave even in the absence of clinical symptoms-silent myocardial infarction. Thus the cases selected had no electrocardiographic- $Q$ wave evidence of myocardial infarction. The definition of sudden death was that of the WHO, namely natural death occurring immediately or within an estimated period of 24 hours after the onset of acute objective or subjective symptoms of ischaemic heart disease. ${ }^{6}$ During the observation period there were 70 sudden deaths with an age distribution at death as follows: less than 40 years, three men (4\%); 40 to 49 years, 13 men (19\%); 50 to 59 years, 30 men (43\%); 60 to 69 years, 20 men (29\%); and 70 to 74 years, four men (6\%).

Necropsies were done in 25 of the 70 cases. Despite the absence of clinical symptoms, $96 \%$ (24/25) of cases had severe coronary atherosclerosis as evidenced by lesions reducing coronary artery lumen of greater than $75 \%$ and the other case had moderate- 50 to less than $75 \%$ luminal narrowing by coronary atherosclerosis.

\section{Left axis deviation}

The mean frontal plane $Q R S$ vector was determined from the limb leads using a hexaxial reference system. ${ }^{7}$ The vector was calculated to the nearest $15^{\circ}$ because, as pointed out by others, ${ }^{8}$ this is a reasonable limit of precision for the standard electrocardiogram.

The definition of left axis deviation was (1) a mean frontal plane $Q R S$ vector of $-45^{\circ}$ to $-90^{\circ}$; (2) a $Q R S$ duration of $110 \mathrm{~ms}$ or less, and (3) the absence of Wolff-Parkinson-White syndrome, complete left bundle-branch block, and complete right bundlebranch block.

During the 30 year observation period 286 men fulfilled the clinical and electrocardiographic criteria. The age distribution at detection of the electrocardiographic abnormality was 20 to 29 years, 24 men; 30 to 39 years, $43 \mathrm{men} ; 40$ to 49 years, $71 \mathrm{men}$; 50 to 59 years, 97 men; 60 to 69 years, 42 men; 70 to 79 years, eight men; 80 years, one man.

\section{Bundle-branch block}

The criteria for the diagnosis of right and left bundle-branch block were outlined by the New York Heart Association ${ }^{9}$ and the Minnesota code. ${ }^{10}$ The criteria include $\mathrm{QRS}$ duration of $0.12 \mathrm{~s}$ or greater and for right bundle-branch block an $\mathrm{r} S \mathrm{R}, \mathrm{q} R$, or a tall $\mathrm{R}$ wave in V1 and for left bundle-branch block QRS notching and terminal conduction delays in limb (I, aVL) or precordial (V5-6) leads. During the observation period 33 cases of complete left bundle-branch block were detected. The age distribution was 30 to 39 years, three men; 40 to 49 years, seven men; 50 to 59 years, 10 men; 60 to 69 years, 11 men; 70 and over years, two men. For right bundle-branch block, 65 cases were detected and had an age distribution as follows: younger than 20 years, two; 20 to 29 years, $12 ; 30$ to 39 years, eight; 40 to 49 years, $13 ; 50$ to 59 years, $20 ; 60$ to 69 years, eight; 70 and over, two men.

\section{Ventricular extrasystoles}

The criteria for identification of ventricular extrasystoles were (1) different QRS morphology from the dominant rhythm, (2) QRS duration of $0.12 \mathrm{~s}$ or greater, (3) premature in occurrence, (4) no preceding premature $p$ wave. ${ }^{11}$ The age distribution of the 428 cases detected was as follows: younger than 20 years, one; 20 to 29 years, 20 ; 30 to 39 years, 55 ; 40 to 49 years, $89 ; 50$ to 59 years, $177 ; 60$ to 69 years, $76 ; 70$ years and older, 10 men.

\section{Left ventricular hypertrophy}

Voltage criteria for left ventricular hypertrophy were the essential criteria for definition of this entity. One of three criteria had to be satisfied, either $R$ wave in V5 or V6 greater than $26 \mathrm{mV}, R$ wave in aVL greater than $11 \mathrm{mV}$, or sum of $\mathrm{S}$ in V1 and R in V5 or V6 greater than $35 \mathrm{mV} .{ }^{1012}$ Cases were also analysed according to presence or absence of associated ST and $\mathrm{T}$ findings. The age distribution of the 254 cases of increased QRS voltage were as follows: 20 to 29 years, one man; 30 to 39 years, 48 men; 40 to 49 years, 81 men; 50 to 59 years, 79 men; 60 to 69 years, 40 men; 70 years and older, five men.

$S T$ segment and $T$ wave abnormalities

The description of major ST segment and T wave 
deviations was that outlined in the Minnesota code. ${ }^{10}$ They are coded only in the absence of bundle-branch block, left ventricular hypertrophy, and WolffParkinson-White conduction. ST segment abnormalities were defined as equivalent to Minnesota codes 1 to 3 , that is either ST-J depression $1 \mathrm{mV}$ or greater with the ST segment horizontal or downward sloping, or ST-J depression 0.5 to $1.0 \mathrm{mV}$ with ST segment horizontal or downward sloping, or no ST-J depression $0.5 \mathrm{mV}$ but ST segment downward sloping so that it or $\mathrm{T}$ wave nadir is $0.5 \mathrm{mV}$ or greater below the $p-r$ baseline. The age distribution of the 253 cases of ST segment abnormality was for ages 20 to 29 years, one man; 30 to 39 years, nine men; 40 to 49 years, 29 men; 50 to 59 years, 126 men; 60 to 69 years, 71 men; 70 years and older 17 men.

$T$ wave abnormalities were coded as present if the $T$ wave was isoelectric or inverted (Minnesota code 1 to 3 ) in leads I or II or V2 or V3 or any two of V3 to V6. The age distribution of the 440 cases of $T$ wave abnormality was ages 20 to 29 years, eight men; 30 to 39 years, $27 \mathrm{men} ; 40$ to 49 years, $73 \mathrm{men} ; 50$ to 59 years, 217 men; 60 to 69 years, 92 men; 70 years and older, 23 men. The frequency association of ST segment and $T$ wave abnormalities and the clinical thinking that considers them together lead to the combination of both to form one group.

Major ST and T wave changes were subject to data analysis, but $T$ waves were also coded for the presence of minor $\mathrm{T}$ abnormality, namely reduction in $\mathrm{T}$ wave amplitude (Minnesota code $T$ wave code 4 ) in leads $I$, II, V2, and V3 or any two of leads V3 to V6.

DATA ANALYSIS

To account for age and varying lengths of follow-up, after the development of electrocardiographic abnormalities, the person-year exposure to each abnormality within age groups was calculated. The age specific rates of sudden death per 1000 person years of exposure were calculated from onset of each electrocardiographic abnormality and for the entire cohort from the first 12 lead electrocardiogram. The relative risk, namely the sudden death incidence in those with the electrocardiographic abnormality divided by the incidence in those without the abnormality, was also calculated. Hypothesis testing used the $\chi^{2}$ approach. The null hypothesis was rejected if the probability of a type 1 error was less than $5 \%$.

\section{Results}

PREVALENCE OF ELECTROCARDIOGRAPHIC ABNORMALITIES IN SUDDEN DEATH CASES The prevalence of abnormalities on the routine electrocardiograms in men without apparent heart disease who died suddenly is shown in Table 1 . The majority or $71.4 \%(50 / 70)$ of cases had previous electrocardiographic abnormalities. The most frequent findings was ST segment or $\mathrm{T}$ wave abnormalities occurring in $50 \%$ of cases though in only $31.4 \%$ was it classifiable as a major abnormality. Ventricular extrasystoles were the next most frequent finding, then left ventricular hypertrophy, left bundle-branch block, and pronounced left axis deviation. There were no cases with pre-existing complete right bundle-branch block.

\section{ELECTROCARDIOGRAPHIC VARIABLES AND \\ SUDDEN DEATH PREDICTION}

The age adjusted sudden death incidence for those with and without each of the electrocardiographic abnormalities is shown in Fig. 1. The highest sudden

Table 1 Prevalence of electrocardiographic abnormalities in men without apparent heart disease who later died suddenly

\begin{tabular}{lll}
\hline Abnormality & $\%$ & No. \\
\hline ST segment-T wave & 50 & 35 \\
Major & 31.4 & 22 \\
Minor & 18.6 & 13 \\
Ventricular extrasystoles & 15.7 & 11 \\
Left ventricular hypertrophy & 12.9 & 9 \\
QRS voltage criteria and ST segment and & 10.0 & 7 \\
T abnormalities & 2.9 & 2 \\
QRS voltage criteria only & $7 \cdot 1$ & 5 \\
Complete left bundle-branch block & 5.7 & 4 \\
Pronounced left axis deviation & 1.4 & 1 \\
PR interval greater than 0.22 s & 0.0 & 0 \\
Complete right bundle-branch block &
\end{tabular}

These abnormalities coexisted in some patients so that $71.4 \%(50 / 70)$ had one of the above abnormalities and $23.6 \%$ (20/70) had none.

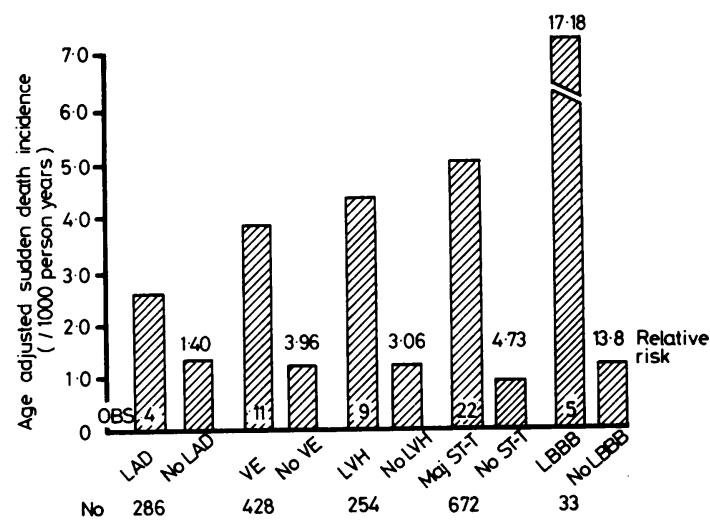

Fig. 1 The age adjusted sudden death incidence for those with and without each of the following electrocardiographic abnormalities: pronounced left axis deviation (LAD), ventricular extrasystoles (VE), left ventricular hypertrophy (LVH), major $S T$ segment or $T$ wave abnormalities (Maj ST-T), and complete left bundle-branch block ( $L B B B)$. The number of sudden death cases observed $(O B S)$ in each subgroup with each

electrocardiographic abnormality and the relative risk for sudden death are also shown. 
death incidence rate was for complete left bundlebranch block which was significantly $(p<0.05)$ greater than the absence of left bundle-branch block. The relative risk for sudden death was 13.8. Major ST segment and $T$ wave abnormalities, increased $R$ wave voltage, and ventricular extrasystoles were all significantly $(p<0.05)$ associated with sudden death with relative risks from 4.8 to 3.7 . Pronounced left axis deviation was not significantly associated with sudden death.

Two of the variables, namely left ventricular hypertrophy and ST segment and T wave changes, could be examined in more detail. For left ventricular hypertrophy, the highest incidence of sudden death was in men in whom increased QRS voltage and ST segment and $T$ wave abnormalities occurred together (Table 2). The next highest incidence of sudden death was in those with increased QRS voltage and no associated ST segment or T wave abnormalities subsequently. To examine the relation between sudden death and the severity and location of $T$ wave abnormalities the small number of cases in each subset made the analysis of proportions preferable. Risk of sudden death increased with increasing severity of $T$ wave abnormality. It was greater with abnormalities in leads V4 to V6, then V2 and V3, then lead II, and lastly lead I (Fig. 2). Combinations of electrocardiographic abnormalities, where relevant, showed a pronounced increase in sudden death risk (Fig. 3). Further subdivision of these combinations was not possible because of the small numbers in many subsets.

\section{Discussion}

This study has demonstrated that certain abnor-

Table 2 Age adjusted incidence of sudden death for left ventricular hypertrophy according to presence or absence of associated $S T$ segment or $T$ wave abnormalities

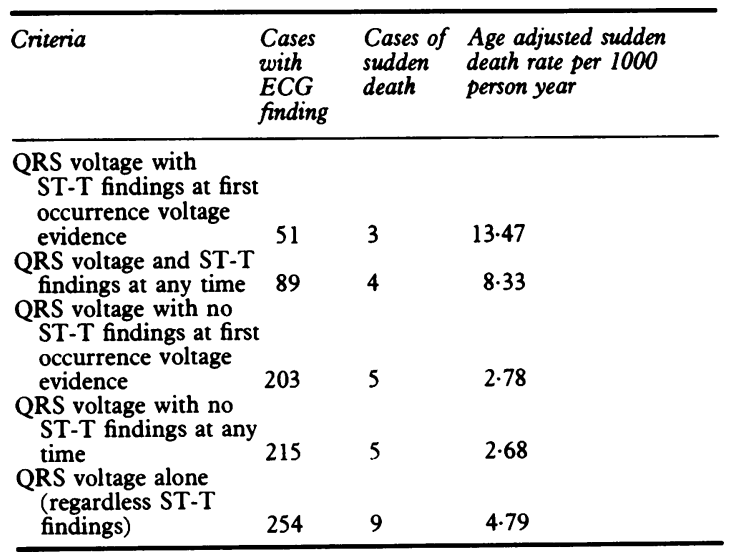

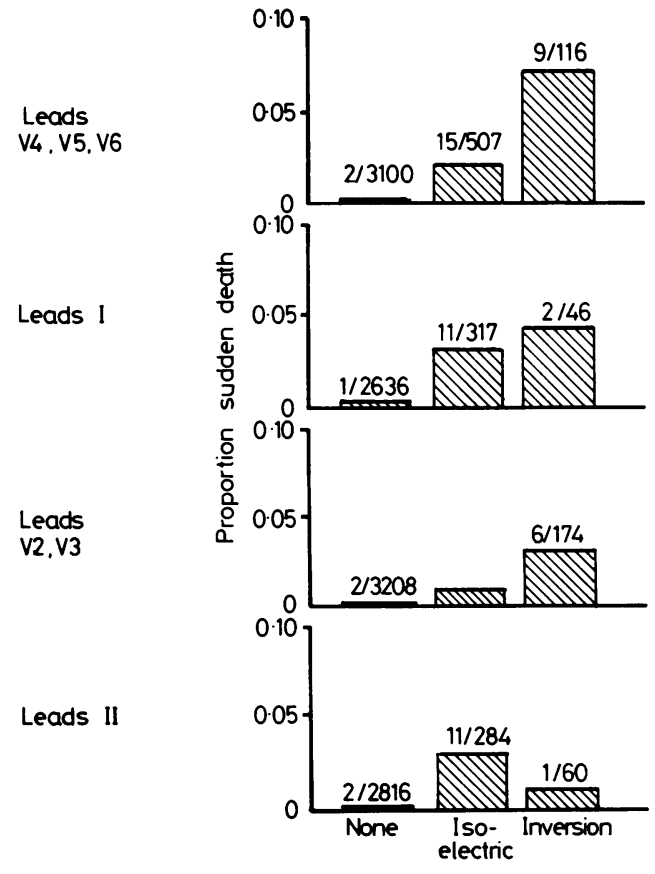

Fig. 2 The proportion of sudden death within 10 years of the occurrence of $T$ wave abnormalities defined by the presence and severity of the $T$ wave findings and the lead(s) in which they occur.

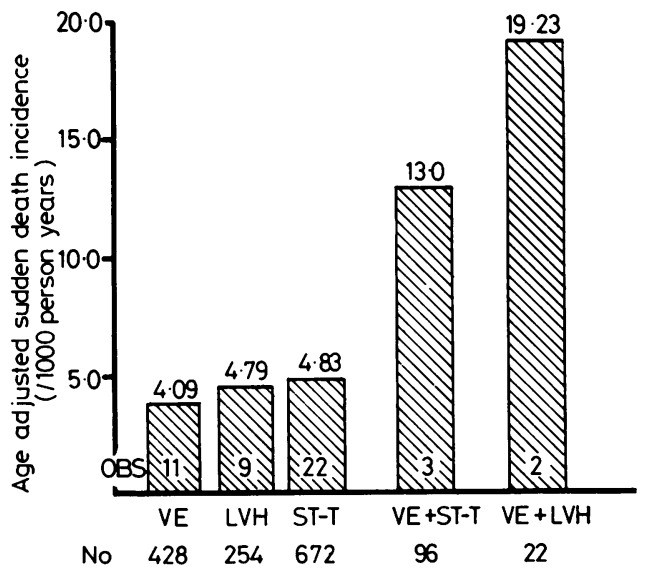

Fig. 3 The age adjusted sudden death incidence for those with combinations of electrocardiographic abnormalities, namely ventricular extrasystoles (VE) plus left ventricular hypertrophy (LVH) or ST segment/T wave abnormalities (ST-T). For comparison, the incidence of sudden death is again shown when the abnormalities occur alone. 
malities detected on a resting electrocardiogram in apparently healthy men are associated with a significantly increased risk of sudden death. Left bundle-branch block, left ventricular hypertrophy, major ST segment and T wave abnormalities, and ventricular extrasystoles occurring individually and combinations of the last three are predictors of sudden death. There are, however, several major caveats with regards to the extrapolation of these results. Firstly, though there is concern that none of the prospective studies of cardiovascular disease epidemiology is representative of the general population ${ }^{13}$ the selective nature of this cohort must be remembered. A strength of this study, however, is the relatively young age at entry and the repeated examinations which permit identification of onset of new abnormalities and assurance that there was no heart disease at entry. Secondly, the incidence rate of sudden death in apparently healthy individuals is low. ${ }^{214}$ Though the numbers of cases of sudden death in men without previous heart disease in our study are comparable with others, ${ }^{14}$ nevertheless the small number of cases overall and especially in groups with combinations of abnormalities suggest that conclusions must be drawn cautiously. Thirdly, the difficulties of longitudinal data analysis become even more complex when electrocardiographic variables are analysed. We chose to classify individuals as abnormal from the first detection of the electrocardiographic abnormality regardless of the findings on subsequent tracings. This was done because some abnormalities such as bundlebranch block are relatively permanent once they occur and others such as ventricular extrasystoles are transient, in part because of the short duration of the resting electrocardiogram. Another reason for this approach is that the occurrence of cardiovascular disease or death in the period between electrocardiographic examinations is a confounding factor in classifications of subsequent presence or absence of electrocardiographic abnormalities. Thus our data must be evaluated within this context. Our classification of electrocardiographic abnormalities is equivalent to the Minnesota code criteria with the following exceptions. Left axis deviation starts from $-45^{\circ}$ rather than from $-30^{\circ}$. Our criteria for ventricular extrasystoles and bundle-branch block are specified in more detail and for left ventricular hypertrophy we do not use $R$ amplitude in limb leads except aVL, but use an additional precordial QRS criterion. For data analysis, cases with $Q$ wave abnormalities consistent with the clinical diagnosis of "silent" myocardial infarction were the only ones excluded because they can be considered to have ischaemic heart disease already and thus have an increased risk of sudden death. Their exclusion must be remembered for comparison with other studies. Another issue is the ever present problem of whether the "apparently healthy individual" truly represents an individual without heart disease. Clinically occult ischaemic heart disease may have been the underlying causative factor for the electrocardiographic abnormalities and thus responsible for the prognosis. From a pragmatic standpoint, however, the electrocardiogram might even be viewed as a test for clinically occult disease and its prognostic ability assessed from that perspective.

The concept that electrocardiographic abnormalities identify those at higher risk of sudden death is not new. Initial investigations of this thesis in population studies supported the concept but included individuals with known ischaemic heart disease. ${ }^{15} 16$ Though there is now stronger evidence supporting the prognostic ability of the electrocardiogram in persons with ischaemic heart disease, ${ }^{17}$ there remain limited data on this subject in apparently healthy individuals.

The results of the present study are consistent with data from Life Assurance Companies that used as the end point primarily total mortality. ST segment and $T$ wave abnormalities were associated with an increased subsequent mortality in several studies ${ }^{18-20}$ as well as an increased incidence of myocardial infarction and mortality from that cause. ${ }^{20}$ Left ventricular hypertrophy ${ }^{18}$ and ventricular extrasystoles ${ }^{182122}$ were both associated with an increased mortality rate. With regards to epidemiological studies of apparently healthy men, most of them have focused on total ischaemic heart disease mortality and not on the incidence of sudden death. The adverse prognosis for ST segment and $\mathrm{T}$ wave abnormalities has been identified by others. ${ }^{23} 24$ There is supporting evidence for left bundle-branch block as an adverse prognostic sign $^{2324}$ which was observed in the Framingham population when persons with and without cardiac disease were combined. ${ }^{25}$ The strength of the relation of ventricular extrasystoles to mortality herein was similar to one study, ${ }^{26}$ and greater than several studies 142324 though similar trends were seen in some. 2324

The value of left ventricular hypertrophy in prognosis observed herein is more consistent with the reports from the Framingham study ${ }^{27}$ than with others. ${ }^{23} 24$ There may be two explanations for this. Studies reporting no value of left ventricular hypertrophy included limb lead criteria of $\mathrm{R}$ amplitude greater than $20 \mathrm{mV}$ in any of leads I, II, III, or aVF while our study and the Framingham study did not use this criterion. In addition, the present study suggests a potential explanation for the apparent differences of opinion as it applies to left ventricular hypertrophy. The Framingham study criteria included not only QRS voltage but also ST and T wave abnormalities, ${ }^{1427}$ while other studies used only voltage 
criteria. ${ }^{23} 24$ We found that the association between sudden death and left ventricular hypertrophy increased with the presence of ST segment and T wave abnormalities. Detailed evaluation of ventricular extrasystoles $^{28}$ or left bundle-branch block characteristics ${ }^{29}$ were not of benefit in increasing ability to predict sudden death. A comparison with two British studies that evaluated the prognostic value of the electrocardiogram is of interest. Tunstall Pedoe ${ }^{30}$ followed, over a four-year period, a cohort of men aged 40 to 59 years, which included those with no evidence of ischaemic heart disease who had been employed in industry and took part in a cardiovascular screening programme. Rose et al. ${ }^{23}$ determined five year total ischaemic heart disease mortality, which included sudden death, in a cohort of male civil servants aged 40 to 64 years. The results of our study and these two 2330 agree that ST segment and T wave abnormalities on the resting electrocardiogram are important predictors of mortality. The importance of left bundlebranch block in our study is consistent with the report of Rose et al. ${ }^{23}$ but not of Tunstall Pedoe. ${ }^{30}$ In contrast to both of these studies ${ }^{23} 30$ but not others ${ }^{26}$ we found an increased risk of sudden death in persons with ventricular extrasystoles. The value of combinations of electrocardiographic abnormalities for the identification of subsets with increased risk of sudden death is similar to the findings of Tunstall Pedoe. ${ }^{30}$

The findings of the present study that $71 \%$ of cases of sudden death had a previous abnormal electrocardiogram must be interpreted within the context of repeated electrocardiographic examinations but indicate that the electrocardiogram is a relatively sensitive test in prediction of sudden death. ST segment and T wave abnormalities were the most frequently observed, consistent with the findings of Rose et al. ${ }^{23}$ who commented that "even minor $\mathrm{T}$ wave inversion or flattening . . . being predictors even when it was the only recorded abnormality". The high prevalence of these electrocardiographic abnormalities, however, in conjunction with the low incidence of sudden death in apparently healthy men results in a low specificity. Thus a relatively small proportion of men with abnormal electrocardiograms will die suddenly. The absence of data on the potential benefit of identifying these subsets may not result in changes in case management. If the thesis is correct, however, that the ultimate control of ischaemic heart disease mortality in the community will depend on prevention rather than specific therapy for the event, then the identification of high risk groups from electrocardiographic variables may suggest individuals for investigation and evaluation of research strategies for prevention of sudden death.

This work was supported by a grant from the
Department of National Health and Welfare, Ottawa, Ontario, Canada and The Great-West Life Assurance Company, The Murphy Foundation Incorporated, The Manitoba Medical Services Foundation Inc., Winnipeg, Manitoba, Canada.

\section{References}

1 Lown B. Sudden cardiac death; the major challenge confronting contemporary cardiology. Am f Cardiol 1979; 43: $313-28$.

2 Kuller L. Sudden death in arteriosclerotic heart disease. The case for preventive medicine. Am $\mathcal{~ C a r d i o l ~ 1 9 6 9 ; ~ 2 4 : ~}$ 617-27.

3 Paul O. Myocardial infarction and sudden death. In: Braunwald E, ed. The myocardium: failure and infarction. New York: H P Publishing 1974: 273-84.

4 Mathewson FAL, Varnam GS. Abnormal electrocardiograms in apparently healthy people. I, Long term follow-up study. Circulation 1960; 21: 196-203.

5 Rabkin SW, Mathewson FAL, Hsu PH. Relation of body weight to development of ischemic heart disease in a cohort of young North American men after a 26-year observation period: the Manitoba study. Am $\mathcal{F}$ Cardiol 1977; 39: 452-8.

6 Paul O, Schatz M. On sudden death. Circulation 1971; 43: 7-10.

7 American Heart Association committee on electrocardiography. Recommendations for standardization of leads and of specifications for instruments in electrocardiography and vectorcardiography. Circulation 1967; 35: 583-602.

8 Hiss RG, Lamb LE, Allen MF. Electrocardiographic findings in 67,375 asymptomatic subjects. $X$. Normal values. Am F Cardiol 1960; 6: 200-31.

9 New York Heart Association, Criteria Committee. Nomenclature and criteria for diagnosis of diseases of the heart and great vessels. 7th ed. Boston: Little Brown, 1973: 238-52.

10 Rose GA, Blackburn H. Cardiovascular survey methods. WHO Monogr Ser 1968; No. 56.

11 Scherf D, Schott A. Extrasystoles and allied arrhythmias. 2nd ed. Chicago: Year Book Medical Publishers, 1974: 52.

12 Sokolow M, Lyon TP. The ventricular complex in left ventricular hypertrophy as obtained by unipolar precordial and limb leads. Am Heart $\mathcal{f}$ 1949; 37: 161-86.

13 Werkö L. Risk factors and coronary heart disease-facts or fancy? Am Heart $\mathcal{F}$ 1976; 91: 87-98.

14 Kannel WB, Doyle JT, McNamara PM, Quickenton P, Gordon T. Precursors of sudden coronary death: factors related to the incidence of sudden death. Circulation 1975; 51: 606-13.

15 Chiang BN, Perlman LV, Fulton M, Ostrander LD Jr, Epstein FH. Predisposing factors in sudden cardiac death in Tecumseh, Michigan. A prospective study. Circulation 1970; 41: 31-7.

16 Pell S, D'Alonzo CA. Immediate mortality and five-year survival of employed men with a first myocardial infarction. N Engl f Med 1964; 270: 915-22.

17 Coronary Drug Project Research Group. The prognostic 
importance of the electrocardiogram after myocardial infarction. Ann Intern Med 1972; 77: 677-89.

18 Ungerleider HE. The prognostic implications of the electrocardiogram. Am f Cardiol 1960; 6: 35-44.

19 Brandon KF, Neill MH, Streeter GC. The use of the electrocardiogram in twenty-five years of insurance selection. Trans Assoc Life Ins Med Dir Am 1950; 34: 143-60.

20 Kiessling CE, Schaaf RS, Lyle AM. A study of T wave changes in the electrocardiograms of normal individuals. Am F Cardiol 1964; 13: 598-602.

21 Lyle AM. A study of premature beats by electrocardiogram. Trans Soc Actuaries 1950; 14: 493-508.

22 Kirkland HB, Kiessling CE, Lyle AM. The evaluation of certain fundamental electrocardiographic patterns in the selection of insurance risks. Trans Assoc Life Ins Med Dir Am 1951; 35: 86-134.

23 Rose G, Baxter PJ, Reid DD, McCartney P. Prevalence and prognosis of electrocardiographic findings in middle-aged men. Br Heart $\mathcal{F}$ 1978; 40: 636-43.

24 Blackburn H, Taylor HL, Keys A. The electrocardiogram in prediction of five year coronary heart disease incidence among men aged forty through fifty-nine. Circulation 1970; 41 \& 42, suppl 1: 154-61.

25 Schneider JF, Thomas HE Jr, Kreger BE, McNamara PM, Kannel WB. Newly acquired left bundle branch block. The Framingham study. Ann Intern Med 1979; 90: 303-9.

26 Stern S, Stern Z. Prognostic significance of ventricular arrhythmias in relation to sudden death. In: Befeler B, Lazzara R, Scherlag BJ, eds. Selected topics in cardiac arrhythmias. Mount Kisco, New York: Futura, 1980: 151-7.

27 Kannel WB, Gordon T, Offutt D. Left ventricular hypertrophy by electrocardiogram. Ann Intern Med 1969; 71: 89-105.

28 Rabkin SW, Mathewson FAL, Tate RB. Relationship of ventricular ectopy in men without apparent heart disease to occurrence of ischemic heart disease and sudden death. Am Heart f 1981; 101: 135-42.

29 Rabkin SW, Mathewson FAL, Tate RB. Natural history of left bundle-branch block. Br Heart F 1980; 43; 164-9.

30 Pedoe HDT. Predictability of sudden death from resting electrocardiograms. Effect of previous manifestations of coronary heart disease. $\mathrm{Br}$ Heart $\mathcal{F}$ 1978; 40: 630-5.

Requests for reprints to Manitoba Study, University of Manitoba, 770 Bannatyne Street, Winnipeg, Manitoba, Canada. 